\title{
PAISAGENS SOCIOLINGUÍSTICAS EM COMUNIDADES POLONESAS DO INTERIOR DO PARANÁ
}

\author{
Sociolinguistic Landscape in Polish Diaspora Communities of the Interior \\ of Parana State
}

Karolina BIELENIN-LENCZOWSKA Universidade Federal de Santa Catarina, Universidade de Varsóvia k.bielenin@gmail.com https://orcid.org/0000-0002-5472-6240

Luciane Trennephol da COSTA Universidade Estadual do Centro-Oeste - UNICENTRO 1tcosta@unicentro.br https://orcid.org/0000-0002-0223-7787

RESUMO: Os poloneses imigraram em massa para o Paraná nos fins do século XIX e início do século XX, contribuindo para a identidade cultural do estado na culinária, na arquitetura, nas festas religiosas e no uso linguístico. Neste texto, à luz do conceito de paisagem linguística, conforme Landry e Bourhis (1997), apresentamos e discutimos a visibilidade e invisibilidade da cultura polonesa em espaços públicos e privados em comunidades de descendentes poloneses no interior do estado. Apesar da predominância da língua polonesa no modo oral, os registros escritos manifestam-se tanto em túmulos centenários como em representações mais recentes. A análise dos aspectos materiais em espaços públicos demonstra a existência e sobrevivência da língua polonesa nas paisagens sociolinguísticas paranaenses apesar de sua relativa invisibilidade em dados e espaços oficiais. PALAVRAS-CHAVE: Sociolinguística; Grupos Étnicos; Comunidades Polonesas; Diáspora Polonesa.

\begin{abstract}
Polish people immigrated en masse to Paraná in the late 19th and early 20th centuries, contributing to the state's cultural identity in cuisine, architecture, religious festivals and linguistic practice. In this paper, following the concept of linguistic landscape (Landry and Bourhis 1997), we present and discuss the visibility and invisibility of Polish culture in public and private spaces in communities of Polish descendants in the interior of the state. Despite the predominance of the Polish spoken language, written records are manifested both in centuries-old tombs and in more recent representations. The analysis of material aspects in public spaces demonstrates the existence and vitality of Polish language in the sociolinguistic
\end{abstract}


landscapes of Paraná despite its relative invisibility in official data. KEY-WORDS: Sociolinguistics; Ethnic groups; Polish Communities; Polish Diaspora.

STRESZCZENIE: Polacy, którzy masowo emigrowali do stanu Parana w południowej Brazylii na przełomie XIX i XX wieku, współtworzyli tożsamość kulturową stanu w zakresie praktyk jedzeniowych, architektury, świąt religijnych i języka. W niniejszym tekście, powołując się na koncepcję krajobrazu językowego opisanego przez Landry'ego i Bourhisa (1997), przedstawiamy i omawiamy widzialność i niewidzialność polskiej kultury w przestrzeni publicznej i prywatnej w społecznościach potomków Polaków w głębi stanu Parana. Mimo dominacji polszczyzny w komunikacji ustnej, język pisany obecny jest zarówno na ponadstuletnich grobowcach, jak i w nowszych przedstawieniach. Analiza aspektów materialnych w przestrzeni publicznej pokazuje istnienie i trwanie języka polskiego w społeczno-językowym krajobrazie Parany pomimo jego względnej niewidoczności $w$ oficjalnych przestrzeniach i danych. SŁOWA KLUCZOWE: Socjolingwistyka; Grupy etniczne; Krajobraz; Diaspora polska.

\section{MULTICULTURALISMO E PAISAGEM SOCIOLINGUÍSTICA}

A cultura polonesa faz parte da identidade paranaense e faz-se presente na culinária, na arquitetura, nos rituais religiosos e no uso linguístico. A língua polonesa é falada em comunidades do interior paranaense e ainda hoje é a língua materna de brasileiros descendentes de poloneses nessas comunidades (COSTA; LOREGIAN-PENKAL, 2015). É uma das línguas faladas no Brasil além do português e, como outras, sujeita às políticas linguísticas monolíngues e à não legitimidade das línguas minoritárias aqui faladas. O silenciamento linguístico brasileiro foi e é muito grande, não importando o grau de bilinguismo dos grupos étnicos indígenas, europeus ou asiáticos. $\mathrm{O}$ estudo das paisagens sociolinguísticas no país pode contribuir para o resgate das línguas não legitimadas que recebem pouco ou nenhum investimento.

Este estudo constitui uma primeira aproximação a dados da paisagem sociolinguística de comunidades polonesas no interior do Paraná, região que recebeu levas de imigrantes eslavos, poloneses e ucranianos, nos fins do século XIX. O conceito de paisagem linguística abarca os textos escritos encontrados em espaços públicos e privados conforme Landry e Bourhis (1997, p. 25): 
The language of public road sings, advertising billboards, street names, place names, commercial shop sings, and public sings on government buildings combines to form the linguistic landscape of a given territory, region, or urban agglomeration. ${ }^{1}$

A noção de paisagem linguística, segundo estes autores, emergiu na área do planejamento linguístico. Países oficialmente bilíngues, como a Bélgica e o Canadá, foram os primeiros a regular o uso linguístico em espaços públicos, normatizando e definindo a paisagem linguística. Landry e Bourhis (1997) citam o exemplo da Bélgica, país no qual conflitos linguísticos entre comunidades de falantes de francês e comunidades de falantes de flamengo ou neerlandês levaram à divisão em dois territórios monolíngues. Apenas a capital Bruxelas é oficialmente bilíngue e oferece serviços em ambas as línguas aos cidadãos. As fronteiras entre os territórios das duas comunidades, de falantes de francês e os falantes de flamengo, são precisamente demarcadas com o uso linguístico em espaços públicos e privados.

A paisagem linguística tem duas funções básicas: uma função informacional e outra simbólica. A função informacional é como uma marca diferenciadora em um território geográfico habitado por uma dada comunidade linguística. Como os territórios linguísticos são raramente homogêneos, a paisagem linguística fornece informação acerca da composição sociolinguística dos grupos linguísticos que habitam o território em questão. A função simbólica envolve as relações de poder no uso linguístico e o prestígio de determinada língua em dado território. Desta forma, em situações de diglossia, a língua majoritária, usada em situações formais e institucionais, é naturalmente mais encontrada em espaços públicos do que a língua minoritária, usada em situações familiares ou comunitárias.

Inicialmente, a pesquisa de campo quanto às paisagens linguísticas foi conduzida por sociolinguistas, sobretudo nas grandes cidades, e focou-se na análise qualitativa e quantitativa da presença da(s) língua(s) escrita(s) no espaço público. Os elementos analisados eram os sinais que se enquadram nos conceitos "de cima para baixo" e "de baixo para cima" (top-down e bottom-up). Os primeiros deles pertencem à política no que toca ao idioma local e que estão com mais frequência relacionados ao multilinguismo da cidade ou da região, ou, inclusive, ao desenvolvimento do turismo (ou seja, nomes de

\footnotetext{
${ }^{1}$ A linguagem de sinais de trânsito, os cartazes publicitários, os nomes de ruas, os nomes de lugares, os nomes comerciais e os registros em prédios institucionais públicos, todos estes elementos em conjunto, formam a paisagem linguística de um determinado território, região ou cidade. Tradução nossa.
} 
ruas, sinais de trânsito). As placas "bottom-up" são colocadas pelos próprios moradores ou por pessoas que administram os negócios a nível local, e essas placas incluem nomes de lojas e de restaurantes, os grafites e anúncios diversos (BEN-RAFAEL; SHOHAMY; AMARA; TRUMPER-HECHT, 2006). Os estudos das paisagens linguísticas até agora têm se preocupado principalmente com a identidade e a transformação do espaço das cidades, além de prestar mais atenção às tensões e conflitos entre a língua dominante e as línguas minoritárias em dados espaços.

A paisagem linguística pode ser considerada como um importante fator sociolinguístico para a percepção da vitalidade de grupos étnicos em contextos multilíngues. A diversidade de línguas presentes na paisagem linguística pode ser considerada como uma manifestação concreta da diversidade linguística e cultural de grupos étnicos que habitam um território oficial. Sociolinguisticamente, a diversidade linguística em espaços privados ou públicos pode refletir a natureza multilíngue de um lugar. Os pesquisadores defendem que a paisagem linguística pode servir como uma informação importante acerca do poder e status das comunidades linguísticas que habitam determinado território.

Admitindo-se também a existência de graus de bilinguismo (MACKEY, 1968), argumentamos que as práticas linguísticas incluem as práticas sociais e culturais de seus usuários (BIELENIN-LENCZOWSKA, 2020). Na presente pesquisa, pretendemos aplicar as teorias desenvolvidas pelos estudiosos que combinam os métodos etnográficos com a linguística, de acordo com a "segunda onda" de pesquisa sobre paisagem linguística (BLOMMAERT, 2016). Nós argumentamos que o conceito de paisagem linguística, focado exclusivamente na comunicação escrita, é muito estreito. Língua e cultura estão imbricadas e o conceito de paisagem sociolinguística abarca também as linguagens não escritas, visuais e sonoras, bem como as manifestações culturais.

Conforme Blommaert e Maly (2014), a paisagem linguística pode ser considerada como um diagnóstico sociolinguístico de determinada área. Para estes autores, o conceito de paisagem linguística concede saliência às diferentes formas de letramentos existentes em determinado lugar. Letramento aqui considerado em uma perspectiva ampla, conforme Street (STREET; BAGNO, 2006) como práticas sociais que envolvem textos escritos ou orais e que estão associadas a determinadas identidades e expectativas sociais acerca dos comportamentos e papéis a ser desempenhados socialmente. Nessa perspectiva, as práticas sociais são constitutivas da identidade.

Uma análise meramente quantitativa da paisagem linguística de uma dada área pode pecar em não explicar como a presença e distribuição das línguas pode estar conectada com populações e comunidades específicas e as relações entre elas ou com 
os padrões de interação social entre esses grupos. Assim, faz-se necessária uma análise qualitativa multimodal dos elementos textuais, orais e escritos, pictóricos e rituais para um quadro da paisagem sociolinguística de uma dada comunidade.

Os elementos de uma paisagem sociolinguística podem ser analisados em três eixos: passado, futuro e presente. O eixo do passado pode apontar para as origens e modos de produção desses elementos linguísticos, o eixo do futuro aponta para o propósito e representação da língua na comunidade e o eixo do presente pode mostrar a visibilidade atual e situação de um grupo linguístico em espaços multiculturais.

A relativa invisibilidade de determinados idiomas não necessariamente significa a falta de seus usuários no espaço da comunidade. O multilinguismo pode ser invisível em espaços institucionais e oficiais, como acontece no Brasil, mas vicejar em núcleos familiares e religiosos. As relações de poder manifestam-se através da língua, e a não representação material de determinado idioma pode expressar somente sua posição nas relações de poder.

Considerando então a noção de paisagem sociolinguística, englobando elementos culturais juntamente com elementos propriamente textuais, e a pertinência de uma análise qualitativa, empreendemos neste estudo um quadro da presença e da visibilidade da língua polonesa em espaços públicos e privados de comunidades de descendentes poloneses no interior paranaense.

\section{LINGUA POLONESA NO INTERIOR PARANAENSE}

Sabemos que o povo polonês imigrou em massa para o sul do Brasil nos fins do século XIX e início do século XX, fazendo com que o período compreendido entre 1889 e 1892 ficasse conhecido como a 'febre brasileira' (WACHOWICZ, 2002, p. 18). Essa migração fez parte da colonização em massa da Europa, relacionada com as mudanças econômicas e políticas na segunda metade do século XIX. A partir dos meados da década de oitenta do século XIX até aos meados da década de noventa, havia uma crise agrária (chamada da crise dos grãos) europeia, em consequência dos grãos mais baratos vindos dos Estados Unidos e do Canadá que inundaram os mercados da Europa Ocidental. Consequentemente, houve uma queda dos preços dos grãos na Europa. No Brasil, por sua vez, após a abolição, havia uma necessidade urgente para contratar a mão-de-obra que poderia ser utilizada nas plantações do café e também na agricultura, lembrando que, naquela época, o país passava pelo processo de modernização. O governo do Brasil, para acalmar os plantadores de café que mais sofreram nessa crise, assinou um contrato com três empresas privadas, as quais deviam trazer 50 mil pessoas da Europa. Além 
disso, acreditava-se que os imigrantes poderiam "branquear" a população brasileira (MAZUREK, 2006, p. 33-34). Os camponeses poloneses vinham para o Brasil junto com os imigrantes da Alemanha e da Itália e se dirigiam para o sul, onde recebiam a terra e arranjavam o trabalho como agricultores. Estima-se que, na virada dos anos 80 e 90 do século XIX, desembarcaram no Brasil entre 40 e 80 mil pessoas do Reino da Polônia. Os poloneses colonizaram os três estados do sul do país, isto é, Paraná, Santa Catarina e Rio Grande do Sul. Tais imigrantes desbravaram o interior paranaense e povoaram muitas de suas cidades.

A especificidade da migração dos Poloneses para o Brasil se expressa em vários aspectos. Em primeiro lugar, a migração envolvia toda a família. No Brasil, os imigrantes queriam e podiam tornar-se proprietários rurais. Em segundo lugar, os colonos poloneses não recebiam nenhum apoio do Estado que os enviavam (porque eram sujeitos da Rússia, Áustria ou Prússia). Em terceiro lugar, a grande maioria deles, era analfabeta. Nas pesquisas feitas até agora, encontra-se pouquíssima documentação daquela época como, por exemplo, livros de oração, fotografias ou imagens sagradas. A maioria dos descendentes têm pouco ou nenhum conhecimento sobre as origens dos seus ancestrais sabem apenas que esses vinham da Polônia.

Apesar dessas circunstâncias, os imigrantes poloneses começaram rapidamente a organizar a vida social, construindo igrejas e escolas e estabelecendo associações. A primeira escola polonesa foi fundada no ano de 1876 na colônia Orleans pelo professor Jerônimo Durski, chamado ‘o pai das escolas polonesas' e, em 1937, já eram 349 escolas (WACHOWICZ, 1971, p. 177 e 199). Além disso, entre os anos 90 do século XIX até os anos 40 do século XX, foram lançadas várias revistas polonesas, como, por exemplo, Gazeta Polska w Brazylii (Jornal Polonês no Brasil), Lud (Povo), Polak w Brazylii (Polonês no Brasil) Świt (Amanhecer) (BIELENIN-LENCZOWSKA; STĄPOR, 2017, p. 43). O quinzenal Lud (1920-1940) foi especialmente comum nas colônias e tinha, possivelmente, cerca de 25 mil leitores (GOCZYLA FERREIRA, 2019, p. 40).

A situação dos poloneses e de outros grupos de imigrantes mudou radicalmente com o Decreto-Lei no 406 assinado pelo presidente Getúlio Vargas, que proibiu o uso de outros idiomas além do português em espaços públicos. Escolas e revistas polonesas foram fechadas e em algumas cidades os colonos esperaram até vinte anos por uma escola pública, o que causou analfabetismo e marginalização ainda maior da comunidade polonesa (WACHOWICZ, 1970, p. 92).

Com todo este contexto histórico de intensa colonização em situações precárias e apesar das políticas linguísticas no Brasil, o bilinguismo se perpetuou nas cidades do interior paranaense. Esse contexto de cultura e multilinguismo motivou pesquisadores Revista X, v. 15, n. 6, p. 129-146, 2020. 
da Universidade Estadual do Centro-Oeste a constituírem o Banco de Dados Variação Linguística de Fala Eslava - VARLINFE - com o objetivo de descrever o português falado no Paraná e as possíveis influências das línguas eslavas, polonês e ucraniano, para a sua constituição. O VARLINFE é um banco de dados composto por entrevistas sociolinguísticas de descendentes poloneses e ucranianos com amostras de sete cidades: Cruz Machado, Irati, Ivaí, Mallet, Prudentópolis, Rebouças e Rio Azul. As entrevistas do VARLINFE são um testemunho oral do vigor da cultura polonesa no interior do Paraná. O grau de bilinguismo varia conforme as cidades, sendo mais frequente nas mais interioranas como Mallet e Cruz Machado, cidades nas quais a maioria dos informantes declara-se bilíngue, sendo falante de português e polonês. Pesquisas linguísticas buscam descrever as caraterísticas fonéticas da língua polonesa falada nessas comunidades (COSTA; GIELINSKI, 2014; NIEWIADOMSKI; COSTA, 2018) e demonstram a permanência de um sistema linguístico específico com características da língua polonesa.

Pesquisas antropológicas desenvolvidas por Bielenin-Lenczowska em Rio Claro do Sul, interior do município de Mallet, a partir de 2015 até o presente, abordam práticas e ideologias linguísticas, bem como a linguagem como patrimônio cultural dos brasileiros de origem polonesa. Tais pesquisas foram desenvolvidas com a metodologia de entrevistas biográficas, em particular aquelas com os elementos de biografias linguísticas (NEKVAPIL, 2003; GOCZYŁA FERREIRA, 2019). A maioria das conversas foi realizada nas casas dos interlocutores em língua polonesa ou fazendo code-switching. Além das entrevistas, foram observadas as atividades cotidianas dos colonos, por exemplo, o trabalho na roça e a preparação de refeições.

De acordo com tais entrevistas e observações, o polonês permaneceu em uso dentro de casa, mas basicamente apenas falado. Nas biografias linguísticas dos interlocutores em Rio Claro ${ }^{2}$, são muito comuns os relatos e lembranças do início escolar, quando na idade de seis ou sete anos, ao começar o ensino fundamental, os informantes ainda não falavam o português. Para os idosos, a principal língua falada até hoje continua sendo o polonês. Nas narrativas, encontramos as lembranças das pessoas cujos pais, avós ou sogros não aprenderam português ao longo de sua vida. Por outro lado, encontramos uma brasileira que não tinha origem polonesa, mas aprendeu o idioma para poder comunicarse com a sua sogra. Nos dias de hoje, os jovens têm mais acesso à educação, são mais escolarizados e familiarizados com a língua escrita, embora muitos deles também lembrem da infância, quando a língua polonesa era falada em casa. Agora essas pessoas não

\footnotetext{
${ }^{2}$ Ver conclusões semelhantes de pesquisas na colônia Dom Pedro II por GOCZYLA FERREIRA (2019).
} 
conseguem se expressar plenamente em polonês, porque não conhecem a sua variedade contemporânea e, em muitos dos casos, não conhecem ninguém com quem poderiam se comunicar em polonês todos os dias. Portanto, na prática, a língua usada é um código misto (BLOMMAERT, 2013), que contém elementos de dialetos poloneses e da língua portuguesa. Convém explicar que falamos dos dialetos poloneses de regiões diferentes e presentes no espaço temporal de 130-140 anos de convivência em uma diáspora. Esses são dialetos de origem da colônia, que eram falados por um determinado grupo social, nomeadamente pelos camponeses. Os imigrantes vieram das regiões diferentes e a fala usada no Brasil foi criada e desenvolvida à base de vários dialetos poloneses em confronto com o português e outras línguas locais.

Apesar da predominância da modalidade oral, o vigor da língua polonesa sobrevive em registros escritos também. Na próxima seção, apresentamos um panorama da presença polonesa na paisagem sociolinguística do interior paranaense.

\section{PAISAGENS SOCIOLINGUÍSTICAS}

Para o mapeamento das paisagens sociolinguísticas que envolvem a língua polonesa, a metodologia que adotamos foi o registro fotográfico de imagens de domínio público combinado com a observação etnográfica, porque o objetivo é descobrir não apenas a presença e a disseminação de diversos idiomas e dialetos, mas também as possíveis ligações com as comunidades e espaços específicos, as práticas organizacionais de diferentes grupos e as relações entre eles (BLOMMAERT; MALY, 2014, p. 3 e 22). É por isso que usamos o termo paisagem sociolinguística para nos referirmos ao conceito paisagem cultural, definido na antropologia social por sua relação com a vida social e cultural das pessoas que moram em um determinado local; suas memórias, narrativas e conceituações locais do espaço (HIRSH; O'HANLON, 1995). Ao mesmo tempo, consideramos a pesquisa sobre uma paisagem sonora bastante inspiradora (SAMUELS et al., 2010), porque as línguas faladas e cantadas no espaço das comunidades polonesas do Paraná são bem audíveis e atestam a presença de descendentes dos imigrantes. Estamos convencidas de que a investigação acerca das práticas linguísticas utilizadas no espaço público, deve concentrar-se não apenas na linguagem escrita, mas também na comunicação falada e outras representações culturais.

Ao olharmos para a paisagem cultural de colônias habitadas por descendentes de poloneses podemos logo perceber que esta região foi fortemente transformada pelos seus habitantes. Os imigrantes que vieram para o sul do Brasil e que trouxeram consigo as suas famílias, colonizaram estas regiões e desenvolveram a agricultura. Cada família 
recebeu ou comprou um lote de terra (10 alqueires, ou seja, $25 \mathrm{ha}$ ), que cultivaram para seus próprios fins. Não há dúvida de que o grande desafio era, conforme mencionam os descendentes de imigrantes e tal como lemos nos registros das fontes, a terra que teve que ser bem preparada para o cultivo, mas os colonos não tinham as ferramentas nem possuíam as habilidades para trabalharem em um ambiente novo e em um clima tão diferente. Muitos deles trouxeram consigo as sementes de plantas e tentaram revitalizar as plantações da mesma forma como o faziam no seu país de origem, isto é, plantar trigo, centeio, lúpulo, beterraba ou batata. É claro que hoje em dia as mudanças globais afetam principalmente a agricultura - as monoculturas de soja e tabaco estão cada vez mais dominando este setor no Brasil. Contudo, até aos dias de hoje, são mantidos muitos hábitos alimentares do local de origem tal como o pierogi, um prato bem comum no Paraná, e o barszcz ou borszcz, que é uma sopa de beterraba (BIELENIN-LENCZOWSKA, 2018). Os sinais da presença de imigrantes da Europa Oriental e Central também são visíveis na arquitetura local, nas decorações das casas ou na presença da imagem de Nossa Senhora de Częstochowa em casas, capelas e igrejas locais. As casas são baixas, apenas de um andar, feitas principalmente de madeira e são bastante coloridas - geralmente azuis ou verdes. Os telhados íngremes e inclinados refletem a herança de seus antepassados que os construíam para protegerem-se da neve (FIGURA 1).

FIGURA 1 - PAISAGEM DE RIO CLARO DO SUL

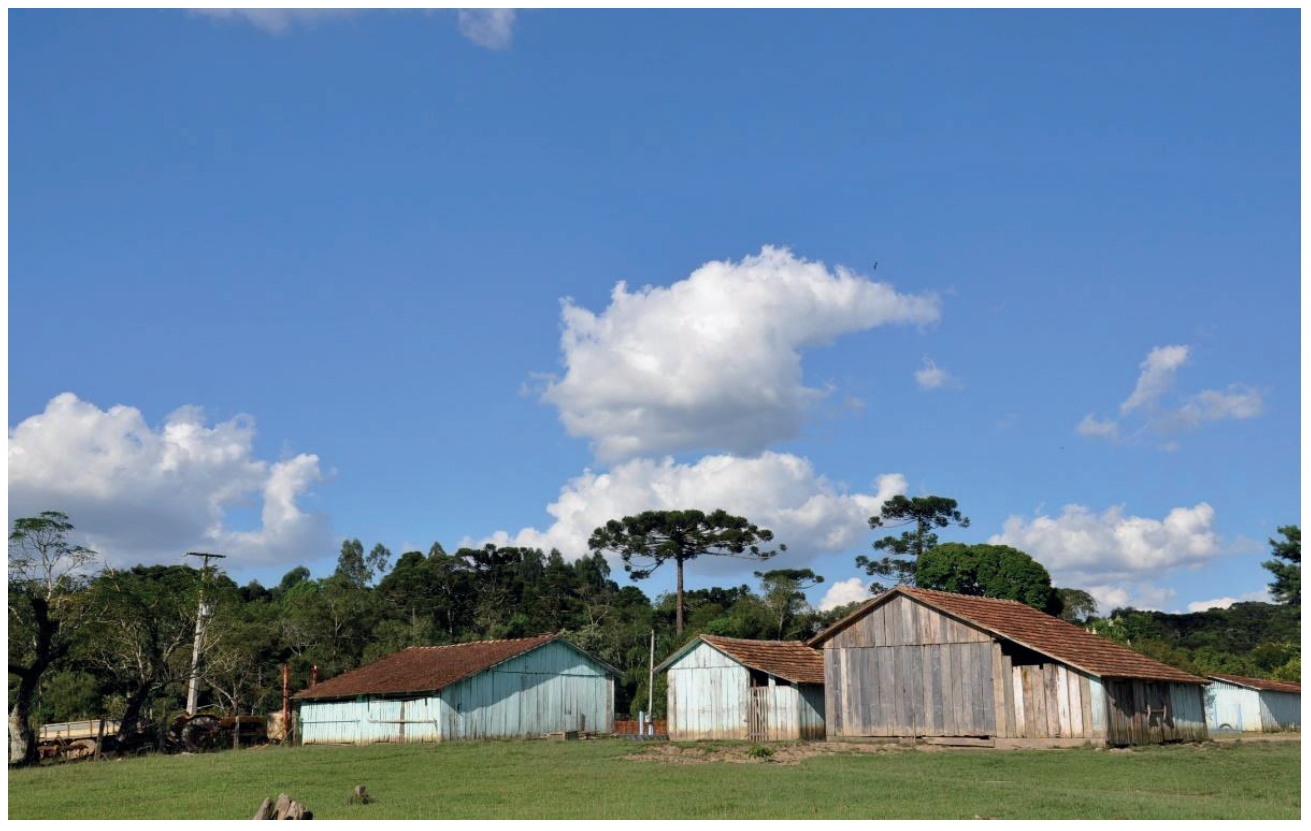

FONTE: Acervo próprio 
Se a cultura polonesa se expressa na culinária e na arquitetura, a língua polonesa é muito menos visível do que audível. Como escrevemos na seção anterior, o bilinguismo polonês-português sobreviveu em muitas comunidades e o polonês permaneceu como um código falado. Isso não significa que não exista idioma polonês no espaço público. A língua polonesa escrita é encontrada em muitos cemitérios nas comunidades de descendentes poloneses do interior paranaense. Em Costa (2019), argumenta-se acerca da forte identidade polonesa que fez imigrantes muito pouco letrados e muitos analfabetos esforçarem-se pelo registro em polonês em suas lápides. A morte é a fatalidade inexorável ao ser humano e todas as culturas têm rituais específicos para esse momento. Morin (1988 apud COSTA, 2019) considera os cemitérios locus privilegiados de marcas identitárias que revelam o intuito e o desespero do ser humano em conservar sua individualidade e identidade mesmo após a morte. A identidade nos túmulos centenários expressa-se em polonês, conforme podemos visualizar na Figura 2, que apresenta a fotografia de um túmulo na cidade de Rio Azul datado de 1917, e na Figura 3, fotografia de um túmulo de casal polonês datado de 1931, na mesma cidade.

Algumas destas placas provam os contatos que surgiram entre o idioma polonês e o português, por exemplo "Tęsknota rodziny" - esta é uma tradução literal da expressão "saudades da família" (FIGURA 4). No entanto, em polonês não se escreve e nem se fala desta maneira.

\section{FIGURA 2 - CEMITÉRIO EM RIO AZUL}

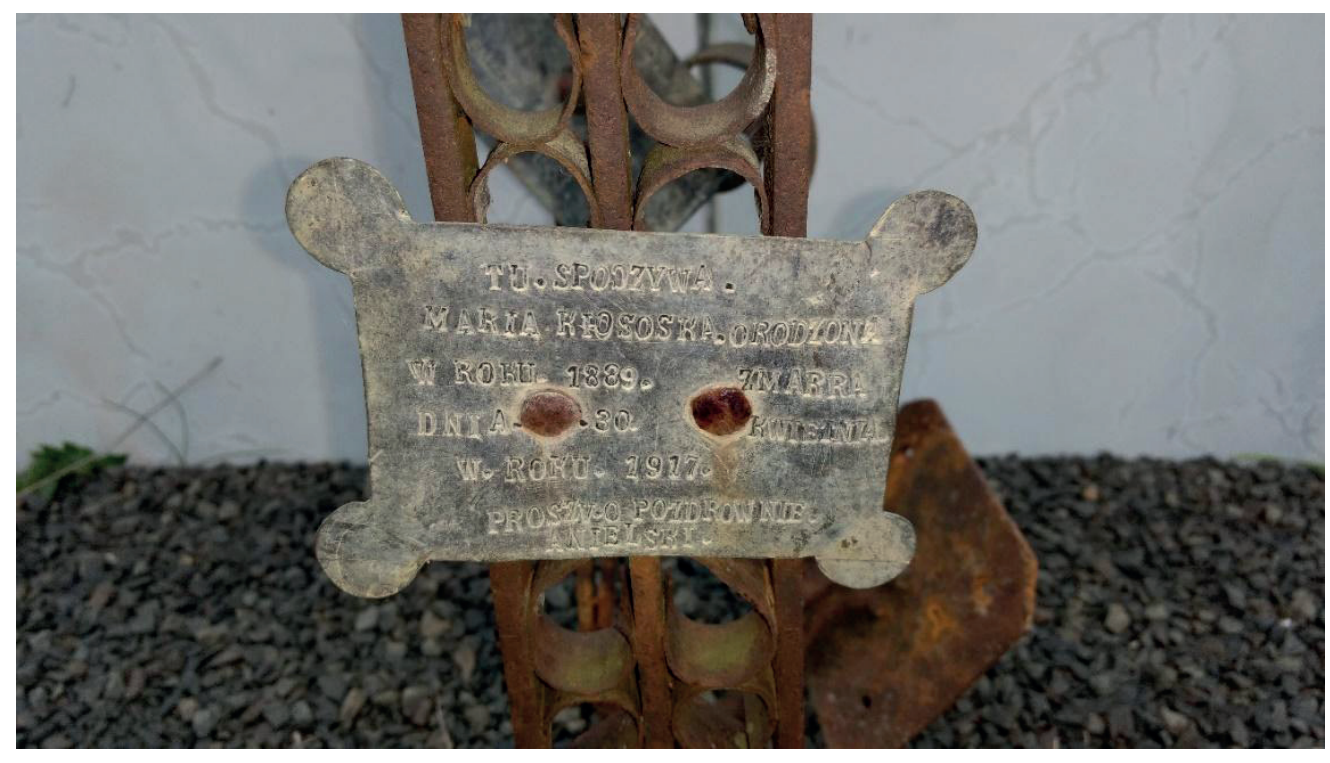

FONTE: Acervo próprio 
FIGURA 3 - TÚMULO DE CASAL EM RIO AZUL

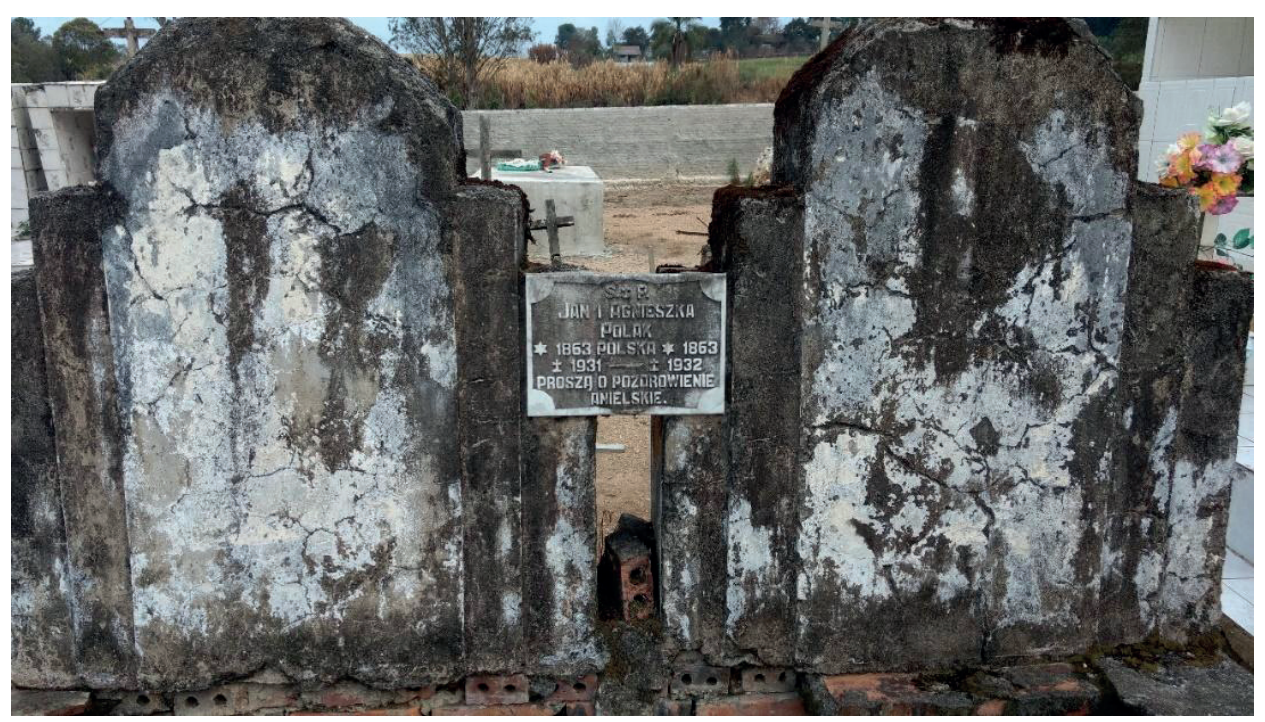

FONTE: Acervo próprio

FIGURA 4 - CEMITÉRIO EM RIO CLARO DO SUL

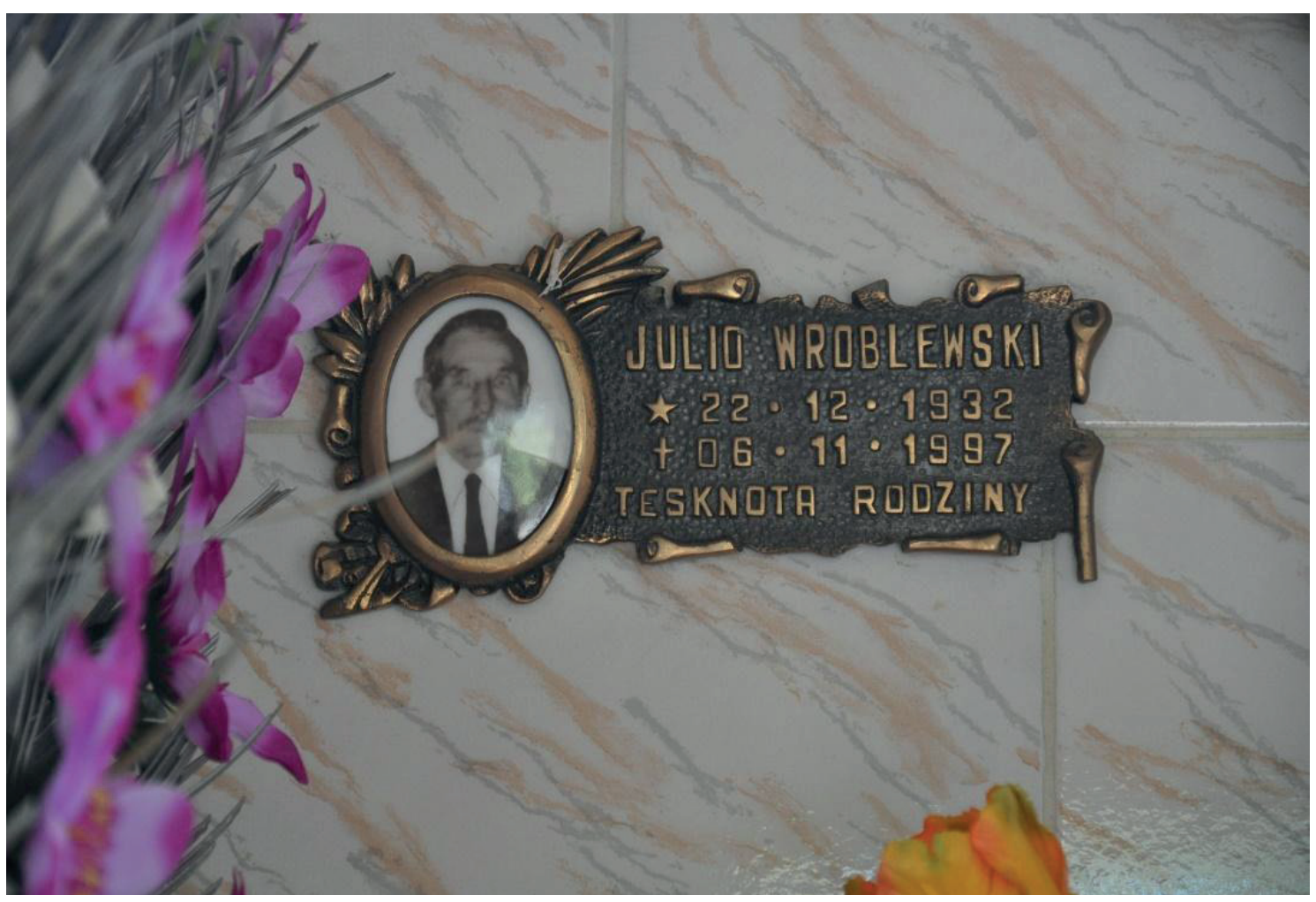

FONTE: Acervo próprio 
Os cemitérios do interior paranaense são como museus a céu aberto e constituem paisagens sociolinguísticas que demonstram a presença histórica da língua polonesa. Registros da língua polonesa escrita encontram-se também em nomes de ruas e pontos comerciais. Em Mallet, importante núcleo de colonização polonesa, já referido neste texto, há uma loja chamada Sklep, palavra que em polonês significa loja, conforme podemos observar na Figura 5

\section{FIGURA 5 - LOJA “SKLEP” EM MALLET}

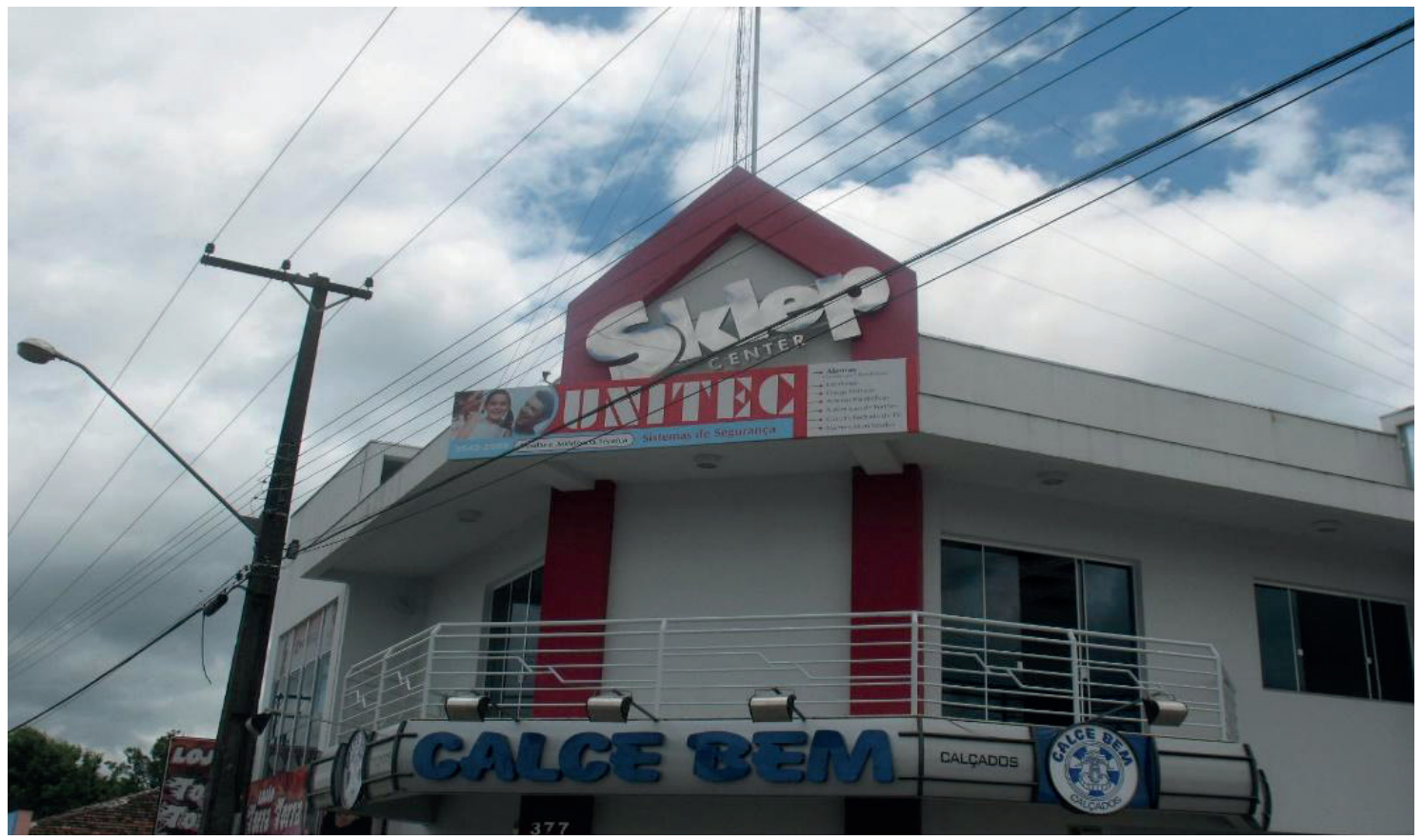

FONTE: Acervo próprio

Outro espaço público que atesta a cultura polonesa nas paisagens do interior paranaense são as placas com os nomes de rua, conforme podemos observar na Figura 6. Como os imigrantes poloneses e seus descendentes fazem parte da história dessas cidades, seus sobrenomes poloneses passaram para as ruas. Em outros espaços particulares também visualizamos a língua, como em um jardim na cidade de Irati, como pode ser visualizado na Figura 7. 


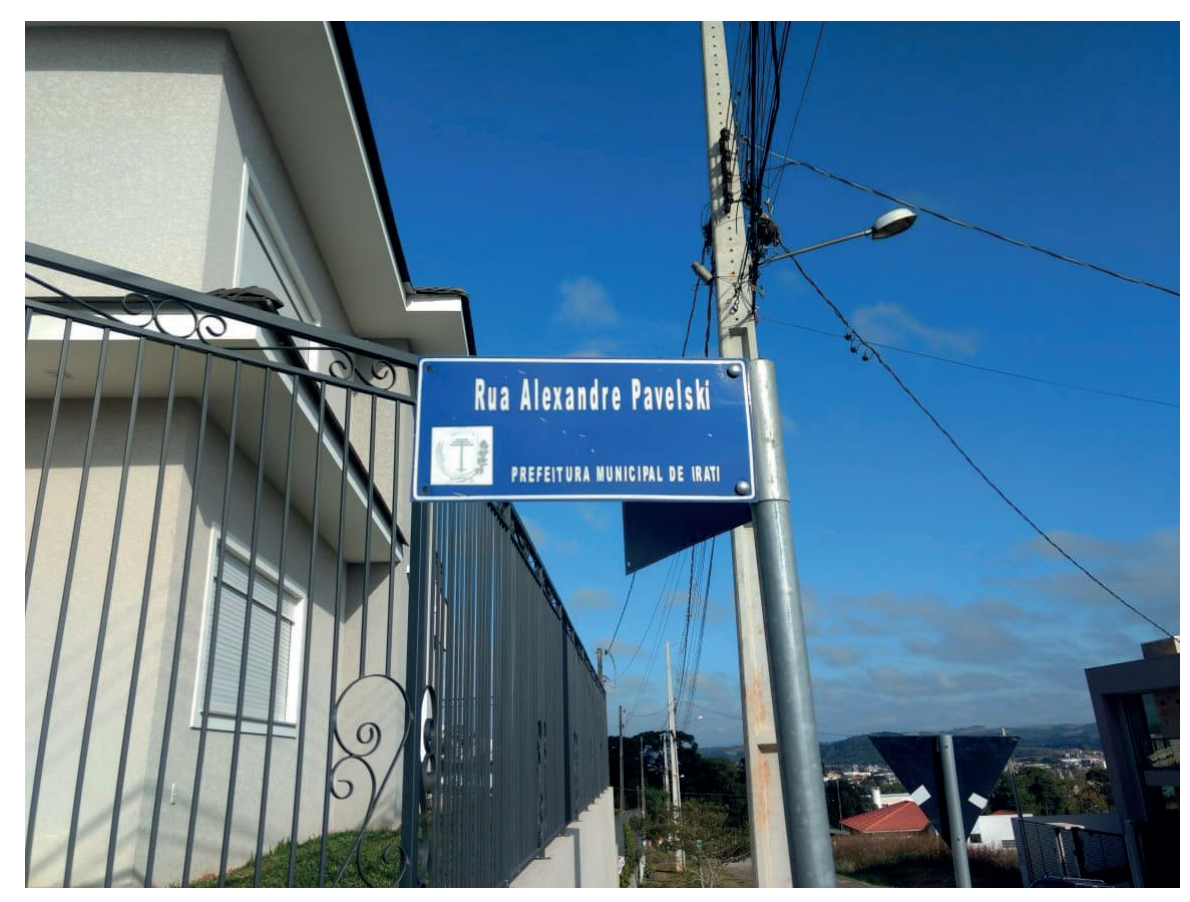

FONTE: Acervo próprio

FIGURA 7 - JARDIM PARTICULAR EM IRATI

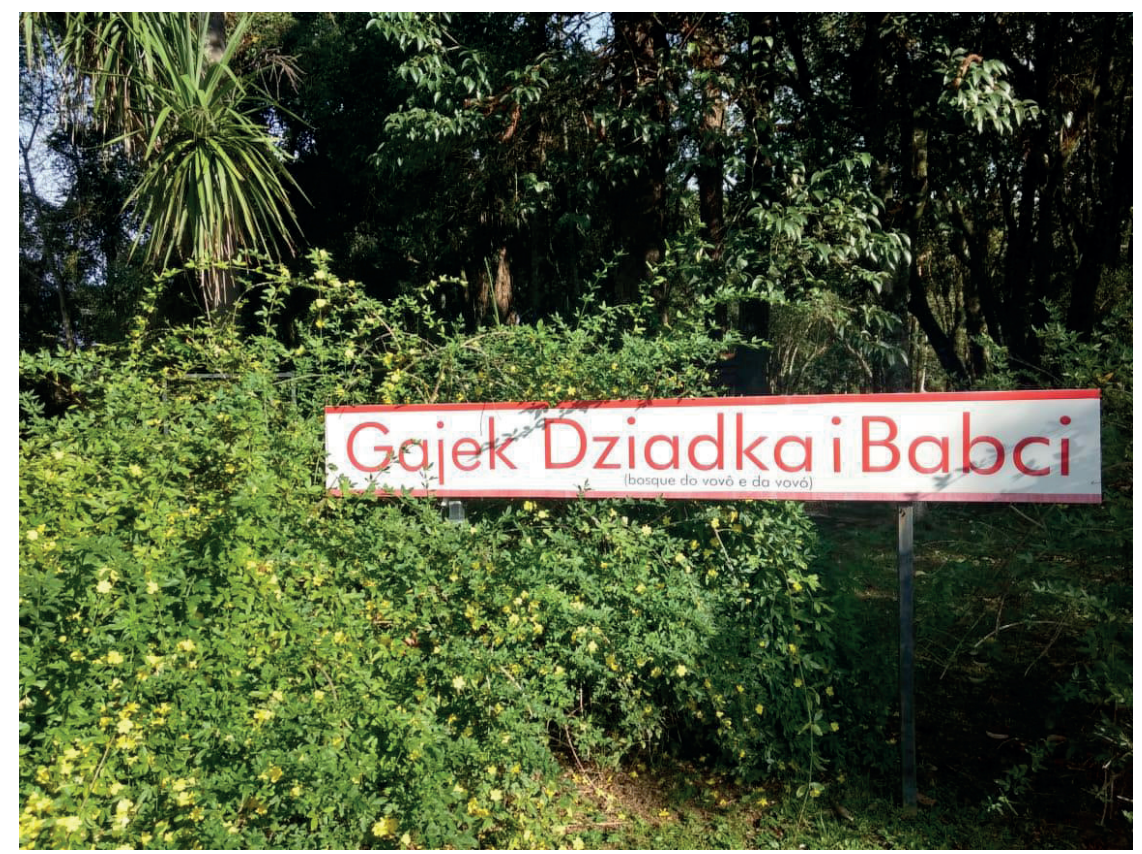

Fonte: Acervo Próprio 
Conforme referenciado na primeira seção desse texto, as paisagens sociolinguísticas incorporam as práticas sociais além do texto escrito. Os grupos folclóricos que ensinam danças com músicas polonesas inserem os descendentes na cultura desde a mais tenra idade. Os ensaios de grupos folclóricos não são apenas dança, mas também aprendizado de idioma. As apresentações também são uma oportunidade de conhecer trajes tradicionais (FIGURA 8) e vários elementos de costumes culturais do país dos antepassados (FIGURA 9). Durante os eventos diaspóricos, podemos encontrar as placas escritas em polonês. Estas geralmente são colocadas ao lado das placas escritas em português e referem-se, por exemplo, aos votos de boa festa (FIGURA 10).

FIGURA 8 - CRIANÇAS EM TRAJES TÍPICOS POLONESES EM MALLET - PR

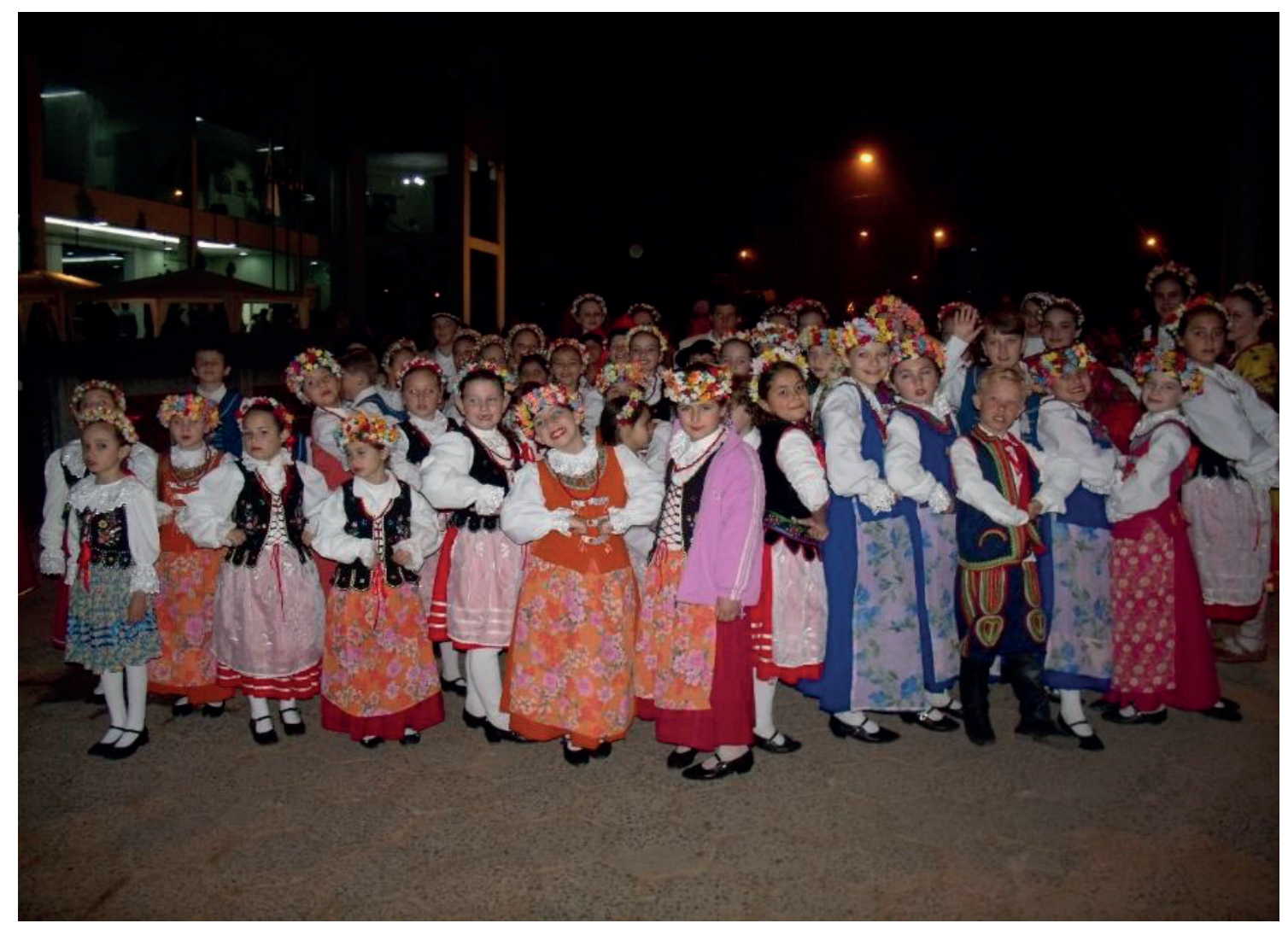

Fonte: Acervo próprio 


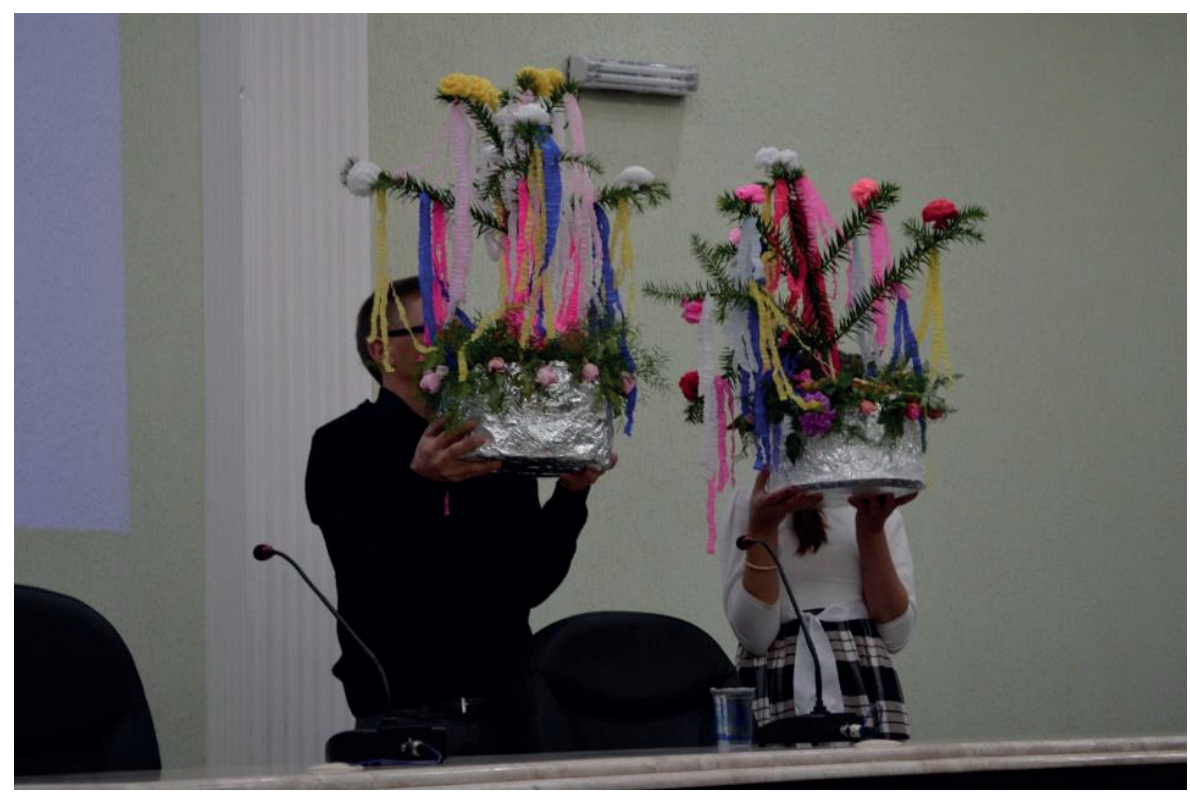

FONTE: Acervo Próprio

FIGURA 10: PLACA DO GRUPO FOLCLORICO „MAZURY” EM MALLET

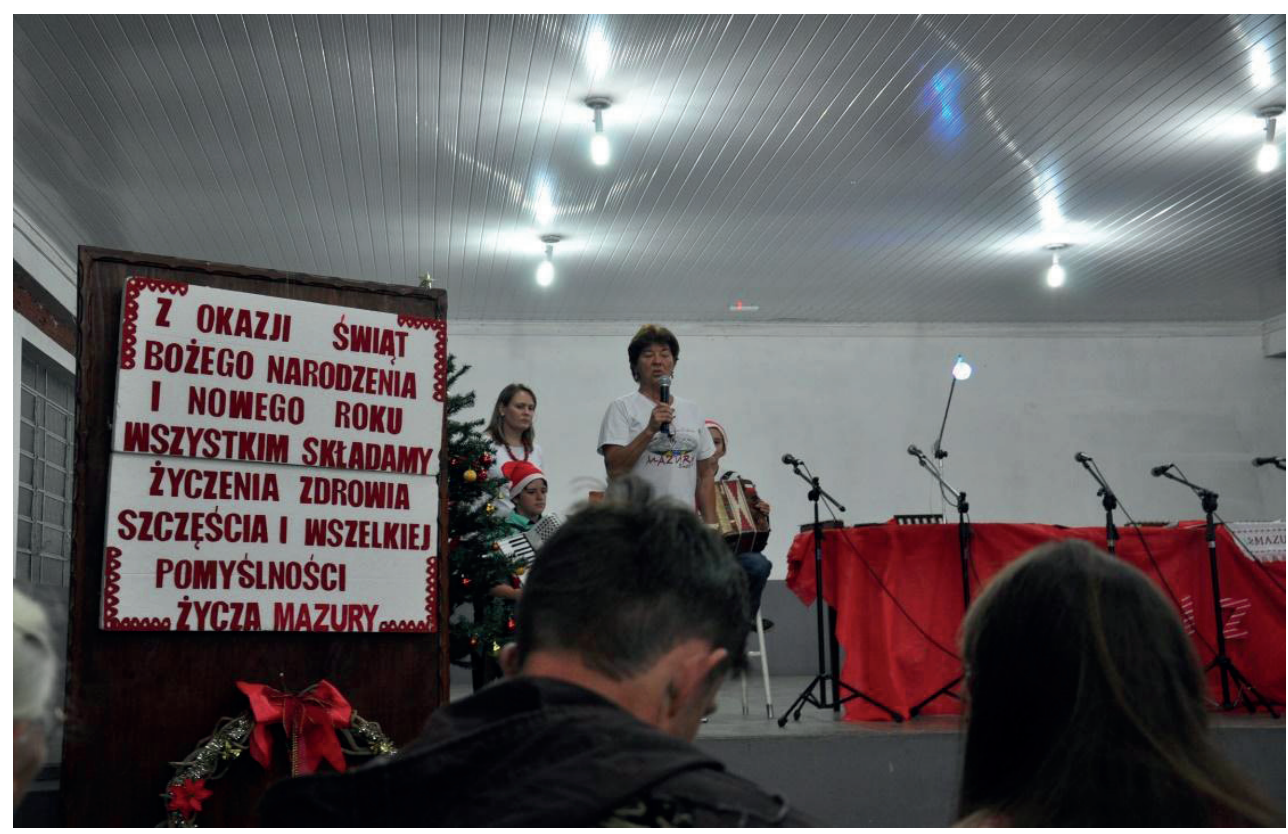

FONTE: Acervo próprio 


\section{CONSIDERAÇÕES FINAIS}

Esta pesquisa analisou qualitativamente elementos da cultura polonesa em paisagens sociolinguísticas de cidades de descendência polonesa no interior do Paraná. Seguindo os estudiosos que combinam os métodos etnográficos com a linguística, as práticas linguísticas englobam as práticas sociais e culturais. $\mathrm{O}$ conceito de paisagem sociolinguística nos permitiu conectar paisagem linguística com cultural e enfatizar a presença da língua falada no espaço público.

Os elementos analisados mostram-se coerentes com os conceitos top-down e botton-up. Do primeiro, vimos que os nomes de rua evidenciam a presença de nomes poloneses na região e poderão ser objeto de uma pesquisa mais detalhada. Do segundo, botton-up, observamos os nomes de estabelecimentos comercias, lápides em túmulos e até placas em jardins. A predominância dos elementos escritos em botton-up é coerente com o status de língua minoritária da língua polonesa nestas cidades. Os rituais culturais, que merecem pesquisas aprofundadas, também atestam a presença da cultura polonesa nas práticas sociais dessas comunidades.

O recorte aqui apresentado demonstra a visibilidade da cultura e da língua polonesa registradas em paisagens sociolinguísticas de cidades do interior paranaense. O panorama mostra que essa língua, essencialmente oral, e a cultura polonesa têm presença forte nas comunidades do interior do Paraná, pois apesar da predominância oral, há registros escritos em variados espaços. As pesquisas das paisagens sociolinguísticas podem contribuir para o conhecimento do multilinguismo brasileiro e para a legitimação das línguas faladas no país, entre elas, a língua polonesa. 


\section{REFERÊNCIAS:}

BEN-RAFAEL E., SHOHAMY E., AMARA M. H., TRUMPER-HECHT N. Linguistic Landscape as symbolic construction of the public space: the case of Israel. International Journal of Multilingualism, 3(1), p. 7-30, abr. 2006.

BIELENIN-LENCZOWSKA, K. A paisagem sócio-linguística: a política, a diversidade e a migração no espaço público. Os estudos de caso. Forum Linguistico, n. 4, 2020.

BIELENIN-LENCZOWSKA K. Pierogi z fiżonem. Praktyki jedzeniowe i tożsamość Brazylijczyków polskiego pochodzenia w południowobrazylijskiej wsi. Studia Migracyjne - Przeglad Polonijny, 1(167), p. 23-47, 2018.

BIELENIN-LENCZOWSKA K., STĄPOR I. Língua como patrimônio cultural. Práticas linguísticas dos descendentes dos poloneses no sul do brasil. Revista del CESLA, n. 20, p. 39-55, 2017.

BLOMMAERT, J. The conservative turn in Linguistic Landscape Studies. Ctrl $+A l t+D e m$ - Jan Blommaert's research blog. 5 jan. 2016. Disponível em: <https://alternativedemocracy-research.org/2016/01/05/the-conservative-turn-in-linguistic-landscapestudies/>. Acesso em 11 abr. 2020.

BLOMMAERT J., MALY I. Ethnographic linguistic landscape analysis and social change: A case study. Tilburg Papers in Culture Studies, 100, p. 1-27, 2014.

COSTA, L.T. A voz do silêncio: Registros de línguas eslavas em cemitérios no interior do Paraná. In: VALLE, I. (Org.) A produção do conhecimento em Letras, Linguística e Artes. Ponta Grossa: Atena Editora, 2019.

COSTA, L. T. e LOREGIAN-PENKAL, L. A coleta de dados do banco VARLINFE variação linguística de fala eslava: peculiaridades e características. Revista Conexão $U E P G$, v. 11, n. 1, p. 100-110, 2015.

COSTA, L. T. e GIELINSKI, M. Detalhes fonéticos do Polonês falado em Mallet. Revista (Con) Textos Linguísticos, v. 8, n. 10, p. 159-174, 2014.

GOCZYŁA FERREIRA A. A presença da língua polonesa na Colônia Dom Pedro II, Campo Largo, Paraná. 2019. Dissertação (Mestrado em Letras) - Setor de Ciências Humanas, Universidade Federal do Paraná, Curitiba.

HIRSCH E., O'HANLON M. (Org.). Anthropology of landscape. Perspectives on place and space. Oxford: Oxford University Press, 1995. 
LANDRY R., BOURHIS R. Y. Linguistic Landscape and Ethnolinguistic Vitality: An Empirical Study. Journal of Language and Social Psychology, 16(1), p. 23-49, 1997.

MACKEY, W. F. The Description of Bilingualism. In: FISCHMAN, J. Readings in the sociology of language. Boston: De Gruyter, 1968.

NEKVAPIL J. Language biographies and the analysis of language situations: On the life of the German community in the Czech Republic. International Journal of the Sociology of Language, 162, p. 63-83, 2003.

NIEWIADOMSKI, S. e COSTA, L. Lenição e epêntese em grupos consonantais tautossilábicos na língua polonesa falada em Cruz machado, Paraná. Revista Palimpsesto, n. 28, p. $415-439,2018$.

SAMUELS D. W., MEINTJES L., OCHOAA.M., PORCELLO T. Soundscapes: Toward a Sounded Anthropology. Annual Review of Anthropology, 39, p. 329-345, 2010.

STREET, B., e BAGNO, M. Perspectivas interculturais sobre o letramento. Filologia E Linguística Portuguesa, 8, p. 465-488, 2006.

WACHOWICZ, Ruy Christovam. As escolas da colonização polonesa no Brasil. Curitiba: Champagnat, 2002. 